\title{
ORDER FIKTIF TERHADAP DRIVER GOJEK DAN UPAYA PERLINDUNGANNYA
}

\author{
Inka Renandani, Adi Suliantoro \\ Fakultas Hukum, Universitas Stikubank (UNISBANK) Semarang \\ Email: reinkaaa10@gmail.com, adisuliantoro65@gmail.com
}

\begin{abstract}
ABSTRAK
Pengangkutan merupakan aspek yang sangat penting keberadaanya dalam masyarakat, baik pengangkutan orang maupun barang. Salah satu perusahaan transportasi online yang terkenal di Indonesia adalah PT.Gojek Indonesia. Pada perkembagannya, muncul perbuatan yang dilakukan oleh oknum masyarakat yang merugikan para driver ojek online, yaitu order fiktif / palsu. Order Fiktif adalah membuat pesanan yang diawali membuat akun palsu melalui aplikasi transportasi online yang dapat merugikan perusahaan.

Permasalahannya adalah bagaimanakah bentuk perjanjian antara driver dengan pengguna dan adakah tanggung jawab dari PT Gojek Indonesia. Metode yang digunakan dalam penelitian ini adalah Yuridis Sosiologis, dengan sumber data berupa wawancara. Hasil Analisa dipaparkan secara deskriptif analitis.

Hasil penelitian menunjukan bahwa belum ada peraturan hukum yang mengatur tentang perlindungan bagi driver Gojek yang mengalami order fiktif. Tetapi dari pihak PT. Gojek memberikan kompensasi berupa uang ganti rugi. Namun hal ini tidak banyak digunakan oleh para driver, karena proses pencairan uang ganti rugi yang membutuhkan waktu, sehingga driver selaku korban lebih memilih membawa sendiri hasil dari pesanan fiktif tersebut atau menjualnya lagi kepada orang lain.
\end{abstract}

\section{Kata Kunci : Perlindungan, Pengangkutan, Gojek}

\begin{abstract}
Transportation is a very important aspect of its existence in society, both the transportation of people and goods. One of the well-known online transportation companies in Indonesia is PT Gojek Indonesia. During its development, there have been actions committed by unscrupulous people in the community that harm online motorcycle taxi drivers, namely fictitious / fake orders. Fictitious Order is an order that starts with creating a fake account through an online transportation application that can harm the company.

The problem is what is the form of the agreement between the driver and the user and is there the responsibility of PT Gojek Indonesia. The method used in this research is sociological juridical, with data sources in the form of interviews. The results of the analysis were presented descriptively and analytically.

The results show that there is no legal regulation that regulates protection for Gojek drivers who experience fictional orders. But from the PT. Gojek provides compensation in the form of compensation money. However, this is not widely used by drivers, because the process of disbursing compensation money takes time, so the driver as the victim prefers to bring the results of the fictitious order himself or sell it to someone else.
\end{abstract}

Keywords: Protection, Transportation, Gojek 


\section{Pendahuluan}

Di zaman modern seperti sekarang ini, pengangkutan adalah salah satu aspek yang sangat penting keberadaanya dalam masyarakat, baik pengangkutan orang maupun barang.Melihat potensi yang ada saat ini banyak sekali perusahaanperusahaan transportasi online yang bermunculan. Seiring dengan berjalanya waktu, para produsen perusahaan transportasi online berlomba-lomba untuk memberikan penawaran terbaik dengan cara mereka masing-masing. PT.Gojek Indonesia mencoba menawarkan jasa pengangkutan baik pengangkutan orang ataupun barang. Salah satu fitur yang ditawarkan yaitu Go- Food.Go-Food adalah layanan pesan antar makanan yang tersedia selama 24 jam. Namun akhirakhir ini sedang marak beredar aksi-aksi yang dilakukan oleh kalangan tertentuk yang dapat merugikan para driver ojek online, yaitu orderean fiktif/orderan palsu. Order Fiktif adalah membuat pesanan sendiri yang dilakukan oleh driver online, yang diawali membuat akun palsu melalui aplikasi transportasi online yang dapat merugikan perusahaan ${ }^{1}$. Dalam hal ini para driver Gojek yang dirugikan tentu sangat memerlukan perlindungan hukum atas apa yang telah mereka alami. Perlindungan hukum adalah memberikan pengayoman kepada hak asasi manusia yang dirugikan orang lain dan perlindungan tersebut diberikan kepada masyarakat agar mereka dapat menikmati semua hak-hak yang diberikan oleh hukum atau dengan kata lain perlindungan hukum adalah berbagai upaya hukum yang harus diberikan oleh aparat penegak hukum untuk memberikan rasa aman, baik secara pikiran maupun fisik dari gangguan dan berbagai ancaman dari

\footnotetext{
${ }^{1}$ Chandra Imelda Noer, ,Analisis Yuridis Tindak Pidana Terkait Order Fiktif Yang Dilakukan Oleh Driver Pt.Gojek Indonesia' (Skripsi Universitas Brawijaya, Malang, 2017).
}

pihak manapun. PT. Gojek Indonesia dalam hal ini sangat berperan karena sebagai produsen atau pemilik perusahaan, PT. Gojek Indonesia harus melindungi dan mengayomi para driver Gojek sebagai mitra kerja mereka.

\section{Metode Penelitian \\ Jenis Pnelitian}

Jenis penelitian ini adalah yuridis sosiologis atau disebut dengan penelitian lapangan. Metode penelitian yang digunakan dalam peneltian ini adalah pendekatan yuridis sosiologis. Pendekatan yuridis sosologis adalah pendekatan yang berpedoman kepada peraturan- peraturan, buku-buku atau literature hukum serta bahan-bahan yang mempunyai hubungan permasalahan dan pembahasan dalam penelitian skripsi dan pengambilan data langsung pada objek penelitian

\section{Spesifikasi Penelitian}

Dalam penelitiana ini digunakan spesifikasi penelitian secara deskriptif analistis. Penelitian deskriptif berkaitan dengan pengkajian secara rinci atau membedakannya dengan fenomena lain ${ }^{2}$.

Tujuan dari penelitian deskriptif ini adalah membuat deskripsi atau gambaran secara sistematis dan akurat berkaitan dengan fakta-fakta, sifat serta kaitanya dnegan antar fenomena yang akan diteliti ${ }^{3}$.

\section{Metode Pengumpulan Data}

Penelitian ini menggunakan jenis data sekunder dan primer, dalam hal ini peneliti melakukan teknik pengumpulan data yang dilakukan melalui wawancara secara langsung antara penulis dengan responden yaitu driver GoJek yang pernah dirugikan akibat orderan fiktif yang dilakukan oleh pengguna jasa mereka.

\section{Metode Analisis Data}

Analisis data bertujuan untuk mengumpulkan data- data yang telah diperoleh oleh peneliti setalah data dari lapangan terkumpul dengan metode pengumpulan data yang telah dijelaskan diaas, maka penulis akan mengelola dan

2 Dr. Sandu Siyoto dan M.Ali Sodik, "Dasar Meodologi Penelitian Hukum dan Jurimetri", (Yogyakarta: Literasi Media Publishing, 2015, hal.8.

${ }^{3}$ Zainudin Ali, Op.Cit, hlm 105 
menganalisis data tersebut engan menggunakan deskriptif kualitatif ${ }^{4}$. Analisis data kualitatif adalah upaya yang dilakukan menggunakan data, dan memilah- milahnya menjadi suatu data yang dapat dikelola, mencari dan enemukan pola, menemukan apa ynag penting dipelajari serta menemukan apa yang dapat diisampaikan kepada masyarakat.

\section{Pembahasan}

\section{Kajian Yuridis Dan Akibat Hukumnya Dari Perjanjian Antara Driver Gojek Dengan Konsumen}

Perjanjian secara umum dapat diartikan sebagai kesepakatan. Suatu perjanjian mengikat para pihak yang melakukanya yang mana sudah diatur dalam klausul perjanjian tersebut. Perjanjian dikatan sah dan mengikat secara hukum bagi para pihak yang melakukanya apabila sudah memenuhi syarat sah nya perjanjian, sebagaimana yang sud ah ditentukan dalam Pasal 1320 Kitab Undang- Undang Hukum Perdata yaitu adanya kata sepakat, kecakapan, hal tertentu dan suatu sebab yang halal. Perjanjian merupakan Undang-Undang bagi para pihak yang melakukannya dan suatu perjanjian tidak boleh bertentangan dengan ketertiban uumum.

\section{Kajian yuridis menurut Kitab Undang- Undang Hukum Perdata}

Transpotasi online memiliki keterkaitan dengan aspek hukum perjanjian.Transpotasi online yang mengikutsertakan para pihak, yaitu perusahaan angkutan umum dan konsumen yang selalu diikuti dengan munculnya suatu perikatan.Dalam hal ini yang termasuk dalam pihak Gojek adalah driver

\footnotetext{
${ }^{4}$ http://etheses.uinmalang.ac.id/281/7/11220001\%20Bab\%203.pdf diakses pada taggal 02-07-2020
}

Gojek tersebut.Karena setelah terjadiny perjanjian antara driver dengan penumpang, maka dua pihak ini lah yang saling berangkutan.

\section{Bentuk Perjanjian Antara Driver Gojek dengan Konsumen}

Tidak ada bentuk perjajian tertulis antara driver dengan konsumen. Jadi terjadinya kesepakatan antara diver dan kosumen dilakukan di dalam aplikasi. Jika konsumen melakukan pemesanan dalam aplikasi dan sudah menemukan driver yang akan mengantarkan pesananya, maka dari situ sudah terjadi kesepakatan antara driver dengan konsumen.

\section{Bentuk Perjanjian Antara Driver Gojek dengan PT Gojek Indonesia}

Syarat untuk bisa menjadi driver Gojek adalah mendaftarkan diri ke kantor Gojek untuk bisa menjadi mitra Gojek. Perjanjian ini disebut Surat Keterangan Kemitraan. Perjanjian ini dibuat untuk keperluan verifikasi pengemudi dalam melakukan kegiatann yang sehubungan dengan kemitraanya dengan Gojek. Surat Keterangan kemitraan ini berisi tentang data diri calon driver, daftar jenis atribut yang diteria driver Gojek dan ketentuanketentuan selama menjadi mitra Gojek.

\section{Akibat Hukum Jika Terjadi Pelanggaran Menurut Kitab Undang- Undang Hukum Perdata}

Menurut pasal 1365 yang berbunyi "Tiap perbuatan melanggar hukum, yang membawa keugian kepada seorang lain, mewajibkan orang yang karena salahnya menerbitkan kerugian itu, mengganti kerugian tersebut" .Dalam hal ini kerugian yang dimaksud adalah kerugian materiin yang dialami driver karena driver tidak bisa mendapatkan uang pengganti dari uang yang sudah dia berikan untuk melakukan pesanan sesuai aplikasi yang dipesan oleh konsumen. Namun pertanggungawaban sulit dimintakan 
karena konsumen yang melakukan order fiktif ini tidak bisa ditemukan karena konsumen tersebut sudah menghapus jejak orderan maupun jejak data yang dimiliki pada aplikasi tersebut.

Kajian Yuridis dan Akibat Hukum menurut Undang-Undang Nomor 8 Tahun 1999 Tentang Perlindungan konsumen

\section{Kajian Yuridis}

Menurut Undang-Undang no 8 Tahun 1999 tentang Perlindungan Konsumen, pembatalan sepihak atau tindakan melakukan order fiktif dinilai tidak sesuai dengan keadaan undangundang. Seperti dalam pasal 5 UndangUndang Nomor 8 tahun 1999 yang mengatur tentang kewajiban konsumen :

Dalam pasal tersebut diakatakan bahwa konsumen harus mempunyai itikad baik dalam melakukan trasaksi pembelian barang/pun jasa dan juga membayar sesuai dengan nilai yang disepakati. Jika konsumen tidak melakukan hal tersebut atau meninggalkan kewajibanya sebagai konsumen , maka dapat dikatakan konsumen tersebut telah melanggar hukum. Dalam Undang-Undang no 8 Tahun 1999 juga tidak hanya berisi tentang perlindungan terhadap konsumen semata namun juga mengenai hak-hak pelaku usaha yang tercantum dalam pasal 6 Undang-Undang No 8 tahun 1999 tentang Perlindungan Konsumen, Dalam pasal tersebut menyebutkan bahwa salah satu hak untuk mendapatkan perlindungan hukum dari tindakan konsumen yang beritikad tidak baik.Orderan fiktif merupkan tindakan konsumen yang termasuk dalam kategori itikad tidak baik.

Selain itu dalam pasal 7 UndangUndang No 8 taun 1999 mengenai kewajiban pelaku usaha : Dari penjelasan Undang-Undang dapat disimpulkan bahwa PT Gojek Indonesia ememiliki kewajiban sebagai pelaku usaha untuk melaksanakan segala hak dan kewajibanya terhadap para Mitra Gojek atau driver yang bekerja dibawahnya.

\section{Akibat Hukum Undang-Undang No 8 Tahun 1999 Tentang Perlindungan Konsumen}

Dalam Undang-undang No 8 Tahun 1999 tentang perlindungan konsumen hanya dijelaskan mengenai sanksi-sanksi yang diperuntukan untuk pelaku usaha saja. Tidak memberikan peraturan atau ketentuan sanksi yang diperuntukan untuk konsumen yang melakukan pelanggaran. Karena dalam kasus ini konsumen lah yang melakukan pelanggaran. kewajiban memberikan kompensasi, ganti rugi dan/ atau penggantian apabila barang dan/atau jasa yang diterima atau dimanfaatkan tidak sesuai hanya dibebankan kepada pelaku usaha.Kewajiban konsumen hanya beritikad baik dalam melakukan transaksi pembelian barang dan/atau jasa, demi keamanan dan keselamatan, namun tidak ada sanksi yang mengatur apabila konsumen beritikad buruk.Sedangkan dalam kasus ini pihak konsumenlah yang melakukan pelanggaran yaitu melakukan pesenanan fiktif yang bearti tidak beritikad baik dalam bertransaksi pembelian barang dan/atau jasa.

Pembuatan perjanjian-perjanjian melalui meda elektronik merupakan konsekuensi dari perkembangan pesat dibidang teknologi informasi telah diantisipasi secara hukum oleh Pemerintah Republik Indonesia. Dan diundangkan dalam Undang-undang Republik Indonesia Nomor 11 Tahun 2008 tentang Informasi dan Transaksi Elektronik dan dilaksanakan melalui Peraturan Pemerintah Republik Indonesia Nomor 82 Tahun 2012 tentang Penyelenggaraan Sistem dan Transaksi Elektronik.

Pada pasal 1 angka 2 UndangUndang Nomor 11 Thaun 2008 tentang Informasi dan Transaksi Elektronik dijelaskan bahwa transaksi elektronik sebagai perbuatan hukum yang dilakukan menggunakan media computer, jaringan computer, dan atau media elektronik lainnya. 


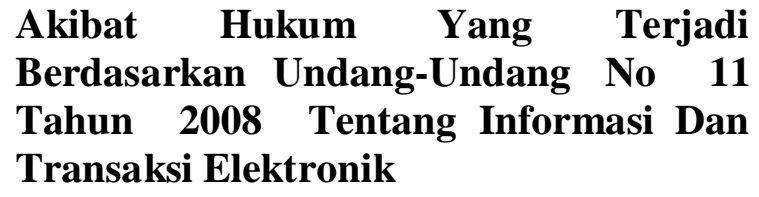

Berdasarkan Pasal 28 Undang-

Undang no 11 Tahun 2008 tentang Informasi dan Transasi Elektronik disebutkan bahwa: "Setiap Orang dengan sengaja dan tanpa hak menyebarkan berita bohong dan menyesatkan yang mengakibatkan kerugian konsumen dalam Transaksi Elektronik."

Sanksi yang dikenakan untuk pelaku perbatan melanggar ketentuan pasal diatas akan dikenai sanksi berupa : Setiap Orang yang memenuhi unsur sebagaimana dimaksud dalam Pasal 28 ayat (1) atau ayat (2) dipidana dengan pidana penjara paling lama 6 (enam) tahun dan/atau denda paling banyak Rp1.000.000.000,00 (satu miliar rupiah)" hal tersebut diatur dalam pasal 45 Ayat (2) Undang-Undang No 11 Tahun 2008 tentang Informasi dan Transaksi Elektronik. Jika seseorang telah dengan sadar melakukan pelanggran atau peruata melawan hukum seerti yang dijelaskan pada pasal diatas, maka orang tersebut akan dikenakan sanksi. Sanksi tersebut diatur dalam pasal 49 Undang-Undang No 11 Tahun 2008 Tentang Informasi dan Transaksi Eeltronik : "Setiap Orang yang memenuhi unsur sebagaimana dimaksud dalam Pasal 33, dipidana dengan pidana penjara paling lama 10 (sepuluh) tahun dan/atau denda paling banyak Rp10.000.000.000,00 (sepuluh miliar rupiah)."

\section{Upaya perlindungan dari pihak Gojek}

Driver Gojek yang mengalami kerugian akibat pemesanan pemesanan makanan oleh konsumen yang tidak bertanggungjawab sangat merasa dirugikan dengan hal ini. Akibat dari kerugian yang dialami oleh driver tersebut tidak hanya kerugian uang saja melainkan juga rugi waktu. PT. Gojek Indonesia berupaya memberikan ganti rugi bagi driver yang mengalami order fiktif. Dengan memenuhi syarat-syarat yang sudah ditentukan oleh pihak Gojek, driver yang menjadi korban order fiktif dapat meminta pertangungjawaban kepada PT.Gojek yang dilakukan oleh konsumen kepada pengemudi Gojek.

Pemberian ganti rugi hanya diberikan kepada pengemudi gojek yang mengalami pesanan fiktif dalam fitur go-food, dan ganti rugi tidak lebih dari Rp. 450.000. Namun menurut salah satu driver gojek yang saya wawancarai, bahwasanya dalam proses ganti rugi yang di berikan dari pihak Gojek itu membutuhkan waktu yang lama, karena hal tersebut banyak dari driver Gojek yang leboh memiih untuk membawa sendri makanan dari order fiktif tersebut untuk sekedar dimakan sendiri mengakibatkan kerugian konsumen dalam Transaksi Elektronik."

\section{Simpulan}

1. Kajian Yuridis dari Hukum Perdata terdapat pada pasal 1320 tentang syarat sahnya perjanjian, pasal 1338 tentang itikad baik dalam melakukan perjanjian, dan pasal 1336 tentang Ganti rugi atau pertanggungjawaban.

a) Berdasarkan pasal 1320, maka perjanjian antara Gojek dengan konsumen sudah sah atau sudah memenuhi persyaratan kecuali syarat cakap, karena dalam hal ini tidak diketahui usiadari konsumen atau pemesan orderan tersebut.

b) Berdasarkan pasal 1338 meegenai itikad baik, itikad baik tidak ada pasa konsumen karena dalam hal ini konsumen dari awal sudah memilikiniat tidak baik yaitu dengan melakukan ordera fiktif.

c) Berdasarkan pasal 1365 tidak dapat dimintakan pertanggungjawaban karena kosnumen tidak diketahui.

2. Kajian Yuridis dari Undang-undang no 8 tahun 1999 tentang Perlindungan Konsumen 
a) Berdasarkan pasal 5 Undang-undan Perrlindungan Konsumen tentangkewajiban konsumen disebutkan salah satunya adalah beritikad baik. Dalam hal ini tidak ada itikad baik dari konsumen karena konsuen telah melkukan perbuatan melwan hukum

b) Berdasarkan pasal 6 Undangundang Perlindungan Konsumen dijelaskan mengenai hak pelaku usaha, Dalam pasal tersebut menyebutkan bahwa salah satu hak untuk mendapatkan perlindungan hukum dari tindakan konsumen yang beritikad tidak baik. Orderan fiktif merupkan tindakan konsumen yang termasuk dalam kategori itikad tidak baik.

3. Kajian Yuridis dari Undang-undang no 11 tahun 2008 tentang Informasi dan Transaksi Elektronik terdapat pada pasal 3 dan pasal 5

a) Berdasarkan pasal 3 Undnagundang no 11 tahun 2008 tentang Inofrmasi dan Transaki Elektronikpemanfaatan

informasi dan transaksi elektronik dilaksanakan berdasarkan asas kepastian hukum.

b) Berdasarkan pasal 5 tentang alat bukti, dimana dalam hal ini sulit untuk menemukan alat bukti karena bukti orderan akan otomatis menghilang ketika terjadi orderan fiktif.

\section{Saran}

1. Disarankan kepada PT.Gojek Indonesia agar dalam pengembalian dana ganti rugi kepada driver Gojek dilakukan dengan waktu yang cepat agar modal yang telah dikeluarkan pada saat membeli pesanan makanan tersebut bisa diputar kembali

2. Disarankan kepada pemerintah atau pihak terkait dalam hal pembutan Undang-Undang untuk dapat membuat Undang-Undang yang mengatur juga tentang sanksi atau akibat hukum yang diberikan kepada pihak konsumen, karena kejahatan tidak hanya dilakukan oleh pihak pelaku usaha saja namun juga dari pihak konsumen,seperti dalam kasus orderan fiktif ini.

3. Disarankan kepada konsumen untuk bijak dalam menggunakan aplikasi

\section{Daftar Pustaka}

Literatur

Dr. Sandu Siyoto dan M.Ali Sodik,"Dasar Meodologi Penelitian Hukum dan Jurimetri", (Yogyakarta: Literasi Media Publishing, 2015

Lexy J, Moleong, Metodologi Penelitian Kualitatif, (Ed. Rev, Jakarta : Remaja Rosdakarya 2010)

Philipus M. Hadjon, "Perlindungan Hukum Bagi Rakyat Indonesia”, (Surabaya: PT Bina Ilmu, 1987)

Phillipus M. Hadjon, Perlindungan Hukum

Satjipto Raharjo, Ilmu Hukum, (Bandung,PT. Citra Aditya Bakti, 2000)

Soejono Soekanto dan Sri Mamudji, Penelitian Hukum Normatif Suatu Tinjauan Singkat, PT Raja Grafindo Persada, Jakarta,2014

Suharsimi Arikunto, Prosedur Penelitian Suatu Pendekatan Praktek, Rineka Cipta, Jakarta, 2012

\section{Perundang-undangan}

Kitab Undang-Undang Hukum Perdata

Undang-undang no 8 tahun 1999 tentang Perlindungan Konsumen

Undang-Undang No 11 Tahun 2008 tentang Informasi dan Trasaksi Elektronik

\section{Website}

http://etheses.uinmalang.ac.id/281/7/11220001\%20Bab\%

203. pdf diakses pada taggal 02-07-2020 https://news.detik.com/berita/d4803482/penyelidikan-order-fiktif-ke-

belasan-driver-ojol-di-serang-akan-

dihentikan diunduh tanggal 05-08-2020

https://news.detik.com/berita/d3556854/sedihnya-driver-gojek-

kehilangan-rp-232-ribu-karena-order$\underline{\text { fiktif diunduh tanggal } 10=-8-2020}$ 
https://www.gojek.com/id/terms-ofservice/diunduh tanggal 28-07-202 